\title{
Preventable Urological Complications Post Kidney Transplant with Modified Lich-Gregoir Technique for Ureteroneocystostomy
}

Zi Qin Ng${ }^{1}$, Bulang $\mathrm{He}^{1,2}$, Lingjun Mou${ }^{1}$, Luc Delriviere ${ }^{1,2}$, Jeffrey M Hamdorf ${ }^{2}$

${ }^{1}$ WA liver and Kidney transplant service, Surgical Department, Sir Charles Gairdner Hospital, Western Australia

${ }^{2}$ School of surgery, The University of Western Australia

\begin{abstract}
Aim: Various ureteroneocystostomy techniques for kidney transplant have been described with Lich-Gregoir (LG) being widely employed. However, even with multiple modifications on this technique, urine leakage and ureteric stenosis remain as most common complications. This study aims to evaluate urological complications by using our modified LG technique after kidney transplant.
\end{abstract}

Method: From 26 th January 2010 to $30^{\text {th }}$ May 2014, 206 consecutive kidney transplants were performed at our institute. 124 were deceased-donor and 69 were live-donor kidney transplants; 13 patients received a small tumour excised kidney graft. All transplants except one were done by conventional open surgery. The modification involves an additional stitch placed at proximal part of bladder muscular incision with peri ureteric tissue at the entrance of ureter to bladder. Urological complications were defined as urine leakage or ureteral stricture. The patients were followed-up from 12 to 64 months.

Results: There was no urine leakage in this cohort. One case of ipsilateral dual-kidney transplant developed distal ureteral stricture secondary to a lymphocele that was treated by laparoscopic fenestration. Subsequently, surgical reconstruction of urinary tract was required and success. Seven cases had mild to moderate hydronephrosis identified on CDU; 4 were due to a lymphocele; 3 were secondary to urinary tract stones. Four patients had renal pelvis prominence on $\mathrm{CDU}$, which was spontaneously resolved with satisfactory renal function.

Conclusion: From this study, it is demonstrated that urine leakage can be prevented and ureteric stricture may be minimised by using this modified LG technique. The ureter was always shortened in an adequate length and a ureteric stent was inserted. This modification is simple and reproducible by placing additional two stitches, which secure the potential gap at the entrance of ureter to the bladder.

Keywords: Post kidney transplant; Lich-Gregoir technique; Ureteroneocystostomy

\section{Introduction}

Kidney transplant is the preferred treatment for patients with endstage renal disease (ESRD). There are about 70,000 kidney transplants in the world every year. With the advancement and refinement in surgical techniques over the decades, urological complications especially urine leakage and ureteric stenosis after kidney transplant have reduced tremendously. However, it could be still devastating if it occurs, leading to prolonged hospital stay, and even mortality [1-4].

There are various techniques employed for ureteroneocystostomy in kidney transplantation. Extravesical ureteroneocystostomy has been in favour in comparison with intravesical ureteroneocystotomy in recent systematic reviews [5,6]. Also, systematic review and meta-analysis have supported the placement of ureteric stent for ureteroneocystostomy. In the extravesical approach, Lich-Gregoir (LG) technique has become widely employed due to its advantages of use of a shorter ureter, mimimal bladder dissection, and less complications. Nevertheless, LG technique still has a risk of urine leakage in $1.6 \%$ and ureteric stricture in $1.9 \%$ [5].

The aim of this study is to evaluate a modification of Lich-Gregoir technique in the cohort of 206 consecutive kidney transplants in our institute.

\section{Materials and Methods}

The approval of study was obtained from the hospital quality improvement committee and human research ethics committee. Retrospective review of the medical records of patients who had kidney transplants from $26^{\text {th }}$ January 2010 to $30^{\text {th }}$ May 2014 was conducted and data collection was recorded on the designed spreading sheet.
Two hundred and six kidney transplants were performed during study period. There were 136 males and 70 females. The age was from 3 to 81 years old with average 49.94 years old. Of 206 recipients, 124 were deceased-donor (DD) kidney transplants, 69 were live-donor (LD) kidney transplants and 13 patients received kidney transplant by using a small tumor excised kidney graft [7]. Laparoscopic or retroperitoneoscopic donor nephrectomy was routinely performed for live kidney donors [8]. The majority of patients had their first kidney transplant, whereas 33, 4 and 1 patients received second, third and fourth transplant respectively. In addition, there were 9 recipients who had dual kidney transplantation (Table 1).

All kidney transplants were performed by conventional open surgery except one kidney transplant was done laparoscopically via the extraperitoneal approach [9]. The ureteroneocystotomy was performed using our modified Lich-Gregoir technique. Briefly, the bladder is distended by running $150 \mathrm{ml}$ of mythelene blue stained normal saline into the bladder. The bladder muscular layer is incised $3 \mathrm{~cm}$ in length at lateral-posterior part of the bladder. The proximal two thirds of the muscular incision is incomplete leaving a very thin layer of muscle with

*Corresponding author: Bulang He, Surgical Department, Consultant transplant urologist, Sir Charles Gairdner Hospital, Hospital Avenue, Perth, Australia, Tel: +61422599441; E-mail: bulang.he@health.wa.gov.au

Received: November 18, 2015; Accepted: January 26, 2016; Published February 02, 2016

Citation: Zi Qin Ng, Bulang He, Lingjun Mou, Luc Delriviere, Jeffrey M Hamdorf (2016) Preventable Urological Complications Post Kidney Transplant with Modified Lich-Gregoi Technique for Ureteroneocystostomy. J Transplant Technol Res 6: 156. doi:10.4172/21610991.1000156

Copyright: $\odot 2016$ Bulang $\mathrm{H}$, et al. This is an open-access article distributed under the terms of the Creative Commons Attribution License, which permits unrestricted use, distribution, and reproduction in any medium, provided the original author and source are credited. 


\begin{tabular}{|c|c|c|}
\hline CHARACTERISTICS & \multicolumn{2}{|l|}{ NUMBER } \\
\hline \multicolumn{3}{|l|}{ SEX } \\
\hline MALE & \multicolumn{2}{|l|}{136} \\
\hline FEMALE & \multicolumn{2}{|l|}{70} \\
\hline \multicolumn{3}{|l|}{ AGE } \\
\hline MEAN & \multicolumn{2}{|l|}{49.94} \\
\hline RANGE & \multicolumn{2}{|l|}{$3-81$} \\
\hline \multicolumn{3}{|l|}{ DONOR } \\
\hline DECEASED DONOR (DD) & \multicolumn{2}{|l|}{124} \\
\hline LIVING DONOR (LV) & \multicolumn{2}{|l|}{69} \\
\hline DUAL KIDNEY TRANSPLANT & \multicolumn{2}{|c|}{6 including 1 Dual Paediatric kidneys } \\
\hline TUMOUR EXCISED KIDNEY & \multicolumn{2}{|c|}{13} \\
\hline \multicolumn{3}{|l|}{ POSITION OF TRANSPLANT } \\
\hline RIGHT ILIAC FOSSA & \multicolumn{2}{|l|}{152} \\
\hline LEFT ILIAC FOSSA & \multicolumn{2}{|l|}{45} \\
\hline \multicolumn{3}{|l|}{ SURGICAL TECHNIQUE } \\
\hline OPEN & 205 & \\
\hline LAPAROSCOPIC & 1 & \\
\hline $\begin{array}{l}\text { COLD ISCHAEMIC TIME (MIN) } \\
\text { - SINGLE KIDNEY } \\
\text { TRANSPLANT } \\
\mathrm{O} \quad \text { RANGE }\end{array}$ & \multicolumn{2}{|l|}{$\begin{array}{l}434.17 \\
40-1764\end{array}$} \\
\hline - $\quad$ DUAL KIDNEY TRANSPLANT & Left: 810.4 & Right: 832 \\
\hline $\begin{array}{l}\text { URETERONEOCYSTOSTOMY TIME } \\
\text { (MEAN) (MINUTES) } \\
\text { ? } \quad \text { RANGE }\end{array}$ & $\begin{array}{l}19.7 \\
8-45\end{array}$ & \\
\hline LENGTH OF STAY (DAYS), MEAN & \multicolumn{2}{|l|}{$4-64(8.1)$} \\
\hline & \multicolumn{2}{|l|}{8.1} \\
\hline FOLLOW-UP (MONTHS) & \multicolumn{2}{|l|}{$12-64$} \\
\hline
\end{tabular}

Table 1: Demographics kidney transplant recipients and characteristics of kidney transplant.

the bladder mucosa while the distal one third of the muscular layer is completely incised and the mucosa is seen bulge out like an "eyeball". This part of bladder mucosa is incised open for ureter-bladder anastomosis (Figure 1). The ureter is trimmed in adequate shorter length and spatulated about $1.2 \mathrm{~cm}$ in length for anastomosis. A ureteric stent was routinely inserted in this cohort. The anastomosis is commenced at the proximal and distal corner using 5/0 PDS Polydioxanone (PDS) suture (Ethicon) (Figure 2). One side anastomosis was continued from distal corner to proximal corner by running 5/0 PDS suture of the bladder mucosa layer to the ureter whole layer, whereas another side anastomosis is continued from proximal corner to the distal corner by running the 5/0 PDS suture in the same fashion (Figure 3). Then the muscular layer is approximated using $3 / 0$ Vicryl suture (Ethicon) in interrupted fashion (Figure 4) and the ureter is tunneled underneath of the muscular layer, but not squeezed tight. An additional stitch was placed at the proximal part of bladder muscular incision with periureteric tissue on each side (Figure 4). A wound drain is routinely placed before the wound closure. The ureteric stent is removed by flexible cystoscopy between four and six weeks after transplant.

The record for cold ischemic time was available for 151 patients. The average cold ischaemic time was 417.86 minutes (from 40 to 1764 minutes). The average cold ischaemic time for dual-kidney transplant was calculated separately where the left and right transplanted kidneys was 810.4 and 832 minutes respectively. Ureteroneocystostomy anastomotic time was recorded in 22 patients. It ranged from 8 minutes to 45 minutes with an average of 19.7 minutes (Table 1).

The immunosuppression is triple regimen with Steroids, Mycophenolate mofetil and Calcineurin inhibitors. The majority of recipients had Basiliximab induction therapy in our cohort. There was no delayed graft function (DGF) in live donor kidney transplant. There

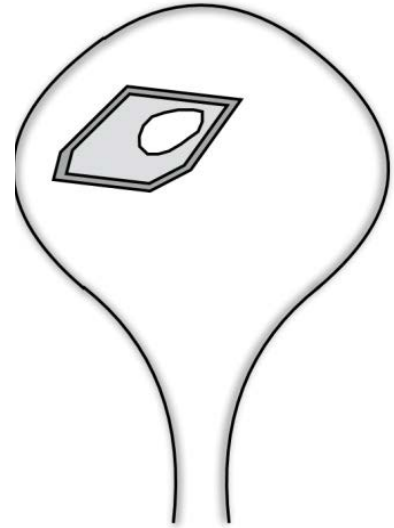

Figure 1: The proximal two thirds of the muscular incision is incomplete leaving a very thin layer of muscle with the bladder mucosa while the distal one third of the muscular layer is completely incised and the mucosa is seen bulge out like an eye-ball. This part of bladder mucosa is incised open for ureter-bladder anastomosis.

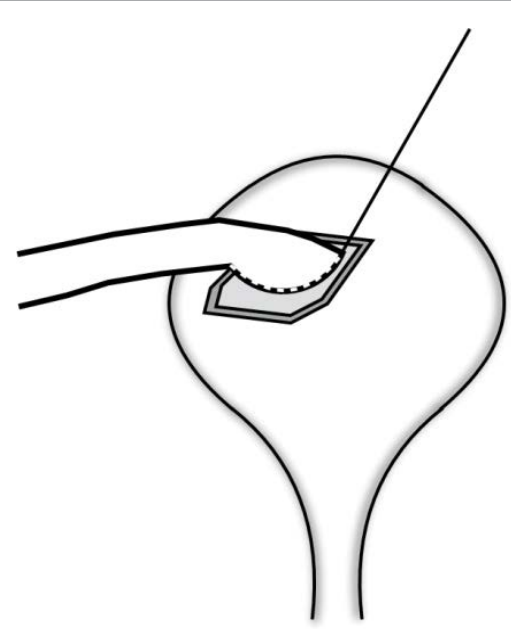

Figure 2: The anastomosis is commenced at the proximal and distal corner using 5/0 PDS Polydioxanone (PDS) suture.

were forty-eight patients experienced DGF in deceased donor kidney transplants and recovered between one and four weeks. Delayed graft function (DGF) is defined as the recipient required dialysis within seven days post kidney transplant [10].

A routine Colour Doppler Ultrasound (CDU) and renal nuclear scan (99mTc MAG3) were obtained on day one post-transplant. CDU was repeated when there was an evidence of graft function deterioration. All other images of the recipients were also reviewed during the study period to include or exclude urological complications post kidney transplant.

The CDU scans were categorized into five groups according to the time period after transplant. Baseline CDU was usually performed from post-transplant day one to day two; followed by the second group which was post-transplant day three to three months; third group which was from three months up to six months, fourth group which was from six months to twelve months and last group which was more than twelve months after transplant. All 206 recipients had baseline 


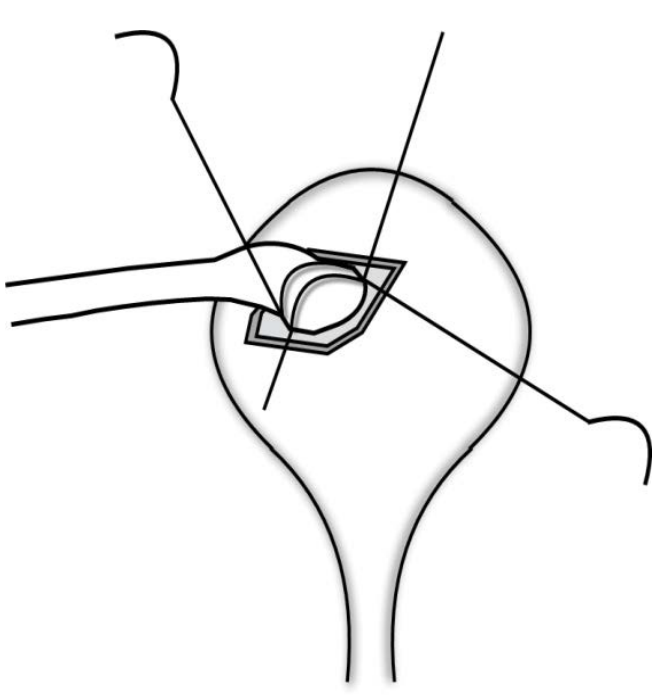

Figure 3: One side anastomosis was continued from distal corner to proximal corner by running 5/0 PDS suture of the bladder mucosa layer to the ureter whole layer, whereas another side anastomosis is continued from proximal corner to the distal corner by running the 5/0 PDS suture in the same fashion.

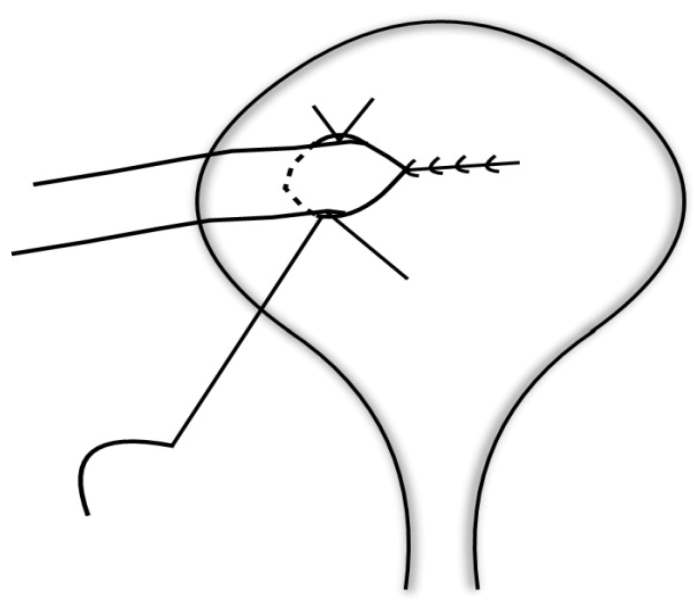

Figure 4: The muscular layer is approximated using 3/0 Vicryl suture (Ethicon) in interrupted fashion and the ureter is tunneled underneath of the muscular layer, but not squeezed tight. The additional stitch was placed at the proximal part of bladder muscular incision with peri-ureteric tissue on each side

\section{CDU. The details of category of CDU are shown in Tables 2 and 3.}

The average length of hospital stay was 8.1 days, ranged from 4 to 64 days. The patients were followed-up regularly in the renal transplant clinic by renal physicians after discharge.

Follow-up period was from 12 months to 64 months. Diagnosis of ureteral obstruction was based on deterioration of kidney graft function, presence of hydronephrosis on CDU and confirmation of stenosis on pyelogram.

\section{Results}

All kidney transplantations were completed successfully using

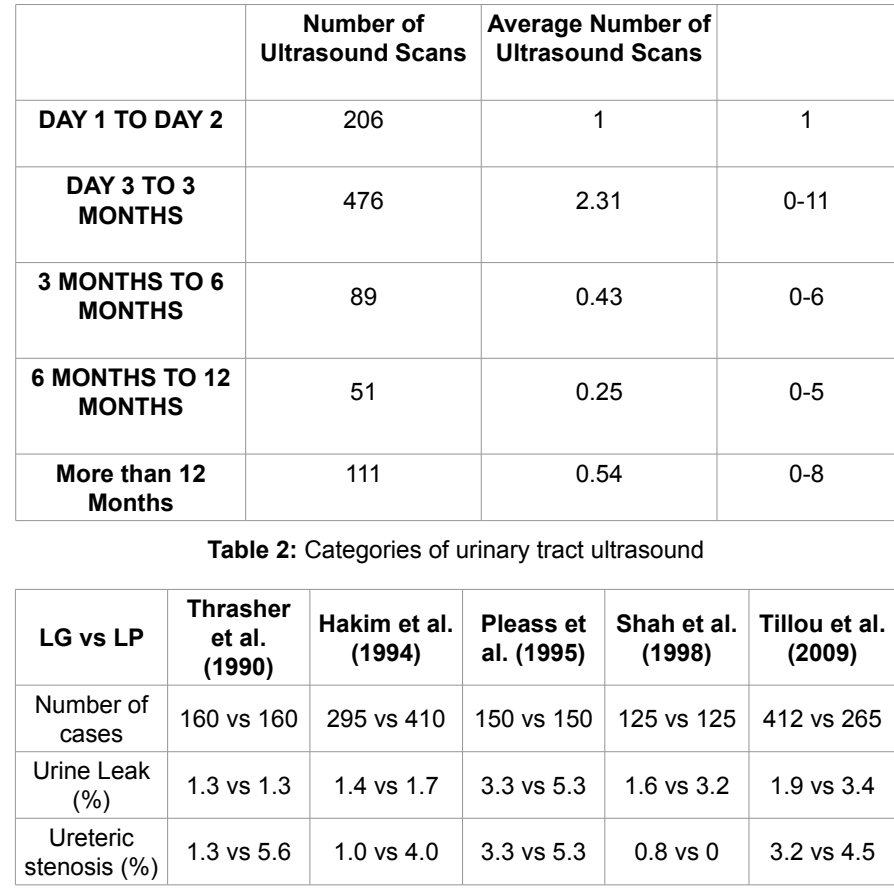

Table 3: Comparative studies of LG versus LP techniques in urological complications (Urine leak and ureteric stenosis).

modified Lich-Gregoir technique for ureteroneocystostomy. Six patients died during follow up due to other medical comorbidities. There were three graft losses; two of them were due to antibody-mediated rejection and one of them was due to dehiscence of the anastomosis between a venous patch of reconstruction for multiple renal arteries and the external iliac artery. There was no occurrence of urine leakage in this cohort. There was one patient who received ipsilateral dual-kidney transplants developed distal ureteral stenosis in each of the graft with association of a lymphocele adjacent to the ureters. The lymphocele resolved completely after laparoscopic fenestration. The distal ureteral stenosis recurred following percutaneous nephrostomy, balloon dilatation of stenosis and re-insertion of a ureteric stent. The surgical urinary tract reconstruction was required. The distal ureters were excised and ureter-bladder re-anastomosis was conducted separately. There was no further complication.

Seven patients were identified with mild to moderate hydronephrosis, five by CDU and two by CT of abdomen. Of the seven patients, four patients were secondary to lymphocele. Three cases were due to ureteric calculi. Of the four lymphoceles, three resolved satisfactory following percutaneous drainage and one required open lymphocele fenestration. On follow-up CDU, the hydronephrosis was resolved without need of further intervention. In other three cases with ureteric calculi, one patient was due to crustation of ureteric stent that was seen during removal of ureteric stent in the 10th week posttransplant. The three calculi were in the mid-ureter with the largest measuring $15 \mathrm{~mm}$ in size. The calculi were passed spontaneously while the patient was waiting for further management. The second patient had a $12.5 \mathrm{~mm} \times 13.5 \mathrm{~mm}$ calculus at the upper pole of kidney graft. The patient underwent extra corporeal shock wave lithotripsy (ESWL) and it was successful. The third case had three calculi from $3.5 \mathrm{~mm}$ to $5 \mathrm{~mm}$ in size in the distal ureter. The cystoscopy and retrograde ureteric stent insertion was attempted but abandoned due to technical difficulty. Fortunately, the calculi were passed spontaneously while the patient was waiting for further management. The hydronephrosis was subsequently resolved on follow up US with satisfactory kidney graft 
function in these 3 cases.

In addition, there were four cases of incidental discovery of renal pelvis prominence on images. All four cases had satisfactory kidney graft function and did not pursue any further investigation. The prominence of renal pelvis was spontaneously resolved on the subsequent follow up imaging.

\section{Discussion}

Our single-centre experience of 206 consecutive kidney transplants has shown that the urological complications of urine leakage can be prevented and ureteric stenosis may be minimized by using our modified Lich-Gregoir technique. In our experience, it is learnt that gentle handling kidney graft, preservation of adequate periureteric tissue, ureter being shorten to a proper length are essential to prevent urological complication post kidney transplantation. LichGregoir technique has been preferred due to its advantages over other techniques [11]. In the modification, one additional suture is placed at the each side of proximal part of the incised muscular layer of bladder to seal the potential gap surrounding the ureter, where the ureter enters to the bladder. Hence, the urine leakage can be ultimately prevented.

Historically, Murray et al. in 1954 successfully implanted the ureter by using Leadbetter-Politano (LP) technique during kidney transplantation between identical twins [12]. LP technique requires one cystostomy to access the interior of the bladder and a second cystostomy to create a new ureteric orifice $[13,14]$. This technique is more laborious and has a higher incidence of haematuria [1517]. Since then, various studies have reported their experience with different ureteroneocystostomy techniques and its associated urological complications. De Campos Freire et al. [18] were the first to utilize extravesical uretereneocystostomy technique in kidney transplantation following the technique described by Lich and Gregoir (hence, LichGregoir technique) for the treatment of vesical-ureteral reflux (VUR) in paediatric population [19]. In the series of 88 patients, the results were commendable with complication rates of $7.6 \%$ urine leakage and $2.5 \%$ of ureteral stenosis [18]. Subsequently, Taguchi and colleagues [20] in 1971 trialed a new extravesical ureteroneocystostomy technique (U-stitch technique) where a U-stitch is used at the distal part of the ureter to anchor it to the anterior bladder wall. The antireflux procedure is performed similarly to LG by imbricating the seromuscular layer over the ureter; it differs from LG technique where it lacks a mucosa to mucosa anastomosis. It has been noted to be superior in operative times but unfortunately it had a higher incidence of haematuria [21,22]. U-stitch technique has also been modified by others. Shanfield used only one stitch but MacKinnon preferred two stitches at the distal part of ureter [23,24]. Finally, the full-thickness technique is reported, in which the ureter is anastomosed to the full thickness of the bladder wall without a tunnel. By using this technique, the urine leakage was $1.1 \%$ and ureteric stricture was $2.5 \%$ in a series of 327 kidney transplants [25].

LG technique has become the technique of option in most centres to reestablish urinary tract continuity in kidney transplantation owing to its simplicity and lower complications rates.

Nevertheless, various modifications have been attempted to further improve urological complication as it remains as one of the most common complications after kidney transplantation with urine leakage ranging from $0.8 \%$ to $9.3 \%$; ureteral obstruction from $1 \%$ to $8.3 \%$ [21,26,27]. Haberal et al. [28] described a Corner-saving technique as a modification to LG with a result of $2.4 \%$ of urological complication ( 1 urine leakage and 1 ureteral stenosis) in a small study population of 82 cases. Khauli emphasized employment of a ureteric stent and using upper ureter in his modification [29]. Our modification aimed to seal the potential gap surrounding the ureter, at the entrance of ureter to the bladder by additional stitch at each side of ureter with bladder muscular layer. This will provide water-tight anastomosis and avoid ureteral obstruction owing to over approximation of bladder muscular layer. In this cohort, there was no urine leakage and no ureteral obstruction resulting from ureteroneocystostomy. One case with dual kidney transplant developed distal ureteral stenosis secondary to ischemic fibrosis.

The effect of vesicoureteral reflux on long-term kidney graft survival is controversial [3]. Vesicoureteral reflux (VUR) was reported in a wide range from $2 \%$ to $86 \%$, depending on the definition, the utility of voiding cystourethrography and the timing of the investigation [3032]. The VUR was not observed as a problem in our cohort by using our modified LG technique. Renal pelvis prominence observed incidentally in our cohort may be due to ureteral oedema that has resolved over time spontaneously. It is understood that the urological complication is multifactorial. Gentle handling the kidney graft and preservation of sufficient peri-ureteric tissue are essential. The most modifiable factor is surgical technique. This modification actually seals the entrance of ureter to the bladder better to prevent the urine leakage, while the ureter is not overly approximated to avoid ureteral stricture.

We routinely use ureteral stent in our practice as it is supported by literature review with less urological complications when compared with no placement of ureteral stent [6]. It is understood that placement of a ureteric stent does predispose some problems such as infection and potential cru station of stent if it is left forgotten. There was a case of urinary tract calculi that was acquired secondary to stent cru station after 10 weeks post kidney transplant. Therefore, early removal of ureteric stent is encouraged within 4 to 6 weeks post kidney transplant. Finally, renal transplant lithiasis is rather an uncommon event and the incidence is from $0.4 \%$ to $1 \%$ [33-36]. The modality for treating urinary tract calculi includes ESWL, Percutaneous nephrolithotomy (PCNL) and endoscopic laser lithotripsy.

\section{Conclusion}

In conclusion, our clinical experience has demonstrated that urine leakage may be preventable and ureteral stenosis can be minimized by using our modified LG technique for ureteroneocystostomy. Our study has the limitation as a retrospective study. However, it is essential by using meticulous surgical technique and gentle handling the kidney graft during kidney procurement, back table preparation and kidney transplantation. Preservation of "golden triangle" and periureteric tissue should be always emphasized. The ureter is preferred to be shorter but not to predispose tension on the anastomosis.

\section{References}

1. Streeter EH, Little DM, Cranston DW, Morris PJ (2002) The Urological Complications of Renal Transplantation: A Series of 1535 Patients. BJU Internat 90: 627-634.

2. Van Roijen JH, Kirkels WJ, Zietse R, Roodnat JI, Weimar W, et al. (2001) Long-term Graft Survival after Urological Complications of 695 Kidney Transplantations. The Jour of Urol 165: 1884-1887.

3. Lamb KE, Lodhi S, Meier-Kriesche HU (2011) Long-term Renal Allograft Survival in the United States: a critical reappraisal. American journal of transplantation: official journal of the American Society of Transplantation and the American Society of Transplant Surgeons 11: 450-462.

4. Englesbe MJ, Dubay DA, Gillespie BW, Moyer AS, Pelletier SJ, et al. (2007) Risk factors for Urinary Complications after Renal Transplantation. American journal of transplantation: official journal of the American Society of Transplantation and the American Society of Transplant Surgeons 7: 1536-1541. 
5. Alberts VP, Idu MM, Legemate DA, Laguna Pes MP, Minnee RC, et al (2014) Ureterovesical Anastomotic Techniques for kidney Transplantation: a systematic review and meta-analysis. Transplant International: official journal of the European Society for Organ Transplantation 27: 593-605.

6. Wilson CH, Bhatti AA, Rix DA, Manas DM (2005) Routine Intraoperative Ureteric Stenting for kidney Transplant Recipients. The Cochrane database of systematic reviews 19

7. He B, Mitchell A, Lim W, Delriviere L (2013) Restored kidney graft from Urologis Referrals for Renal Transplantation. Transplant procee 45: 1343-1346.

8. He B, Mitchell A, Delriviere L (2011) Laparoscopic Donor Nephrectomy. ANZ jour of surg 81: 159-63.

9. He B, Mou L, Sharpe K, Swaminathan R, Hamdorf J, et al. (2014) Laparoscopic Kidney Transplant by Extra Peritoneal Approach: The Safe Transition From Laboratory to the Clinic. American journal of transplantation: official journal of the American Society of Transplantation and the American Society of Transplant Surgeons 14: 1931-1936.

10. Koning $\mathrm{OH}$, Ploeg RJ, van Bockel JH, Groenewegen M, van der Woude FJ, et al. (1997) Risk factors for delayed graft function in Cadaveric kidney Transplantation: a prospective study of renal function and graft survival after preservation with University of Wisconsin solution in multi-organ donors. European Multicenter Study Group. Transplant 63: 1620-1628.

11. El-Mekresh M, Osman Y, Ali-El-Dein B, El-Diasty T, Ghoneim MA, et al. (2001) Urological complications after living-donor renal transplantation. BJU internat 87: 295-306

12. Murray JE, Merrill JP, Harrison JH (1958) Kidney transplantation between seven pairs of identical twins. Ann of surg 148: 343-359.

13. Politano VA, Leadbetter WF (1958) An operative technique for the correction of vesicoureteral reflux. The Journ of urol 79: 932-941.

14. Politano VA, Leadbetter WF (2002) An operative technique for the correction of vesicoureteral reflux. The Journ of urol 167: 1415-1421.

15. Pleass HC, Clark KR, Rigg KM, Reddy KS, Forsythe JL, et al. (1995) Urologic complications after renal transplantation: a prospective randomized trial comparing different techniques of ureteric anastomosis and the use of prophylactic ureteric stents. Transplant procee 27: 1091-1092.

16. Butterworth PC, Horsburgh T, Veitch PS, Bell PR, Nicholson ML, et al. (1997) Urological complications in renal transplantation: impact of a change of technique. British journ of urol 79: 499-502.

17. Hakim NS, Benedetti E, Pirenne J, Gillingham KJ, Payne WD, et al. (1994) Complications of ureterovesical anastomosis in kidney transplant patients: the Minnesota experience. Clin transplant 8: 504-507.

18. Campos Freire J, de Goes GM, de Campos Freire JG (1974) Extravesical ureteral implantation in kidney transplantation. Urol 3: 304-308.

19. Lich R Jr., Howerton LW, Davis LA (1962) Ureteral reflux, its significance and correction. Southern medical journal 55: 633-635.

20. Taguchi Y, Klauber GT, MacKinnon KJ (1971) Implantation of transplant ureters: a technique. The Journ of urol 105: 194-195.

21. Lee RS, Bakthavatsalam R, Marsh CL, Kuhr CS (2007) Ureteral complications in renal transplantation: a comparison of the Lich-Gregoir versus the Taguchi technique. Transplant procee 39: 1461-1464.

22. Ameer A, Aljiffry M, Jamal M, Hassanain M, Doi S, et al. (2011) Complications of ureterovesical anastomosis in adult renal transplantation: comparison of the Lich-Gregoire and the Taguchi techniques. Annals of transplantation: quarterly of the Polish Transplantation Society 16: 82-87.

23. Shanfield I (1972) New experimental methods for implantation of the ureter in bladder and conduit. Transplant procee 4: 637-638.

24. MacKinnon KJ, Oliver JA, Morehouse DD, Taguchi Y (1968) Cadaver rena transplantation: emphasis on urological aspects. The Journ of urol 99: 486-490.

25. Kayler L, Zendejas I, Molmenti E, Chordia P, Schain D, et al. (2012) Kidney transplant ureteroneocystostomy: comparison of full-thickness vs. Lich-Gregoir techniques. Clin transplant 26: 372-380.

26. Thrasher JB, Temple DR, Spees K (1990) Extravesical versus LeadbetterPolitano ureteroneocystostomy: a comparison of urological complications in 320 renal transplants. J Urol 144: 1105-1109.

27. Shah S, Nath V, Gopalkrishnan G, Pandey AP, Shastri JC, et al. (1988) Evaluation of extravesical and Leadbetter-Politano ureteoneocystostomy in renal transplantation. Br J Urol 62: 412-413.

28. Tillou X, Raynal G, Demailly M, Hakam IF, Saint F, et al. (2009) Endoscopic management of urologic complications following renal transplantation: impact of ureteral anastomosis. Transplant procee 41: 3317-3319.

29. Secin FP, Rovegno AR, Marrugat RE, Virasoro R, Lautersztein GA, et al. (2002) Comparing Taguchi and Lich-Gregoir ureterovesical re-implantation techniques for kidney transplants. The Journ of urol 168: 926-930.

30. Dinckan A, Tekin A, Turkyilmaz S, Kocak H, Gurkan A, et al. (2007) Early and late urological complications corrected surgically following renal transplantation. Transplant international: official journal of the European Society for Organ Transplant 20: 702-707.

31. Haberal M, Emiroglu R, Karakayali H, Torgay A, Moray G, et al. (2006) A cornersaving ureteral reimplantation technique without stenting. Transplant procee 38: $548-551$

32. Khauli R (2002) Modified extravesical ureteral reimplantation and routine stenting in kidney transplantation. Transplant international: official journal of the European Society for Organ Transplant 15: 411-414.

33. Engelstein D, Dorfman B, Yussim A, Shmueli D, Bar Nathan N, et al. (1997) A critical appraisal of vesicoureteral reflux in long-term renal transplantation recipients: prospective study. Transplant procee 29: 136-137.

34. Margreiter M, Gyori GP, Bohmig GA, Trubel S, Muhlbacher F, et al. (2013) Value of routine voiding cystourethrography after renal transplantation. American journal of transplantation: official journal of the American Society of Transplantation and the American Society of Transplant Surgeons 13: 130-135.

35. Lee S, Moon HH, Kim TS, Roh Y, Song S, et al. (2013) Presence of vesicouretera reflux in the graft kidney does not adversely affect long-term graft outcome in kidney transplant recipients. Transplant procee 45: 2984-2987.

36. Stravodimos KG, Adamis S, Tyritzis S, Georgios Z, Constantinides CA, et al. (2012) Renal transplant lithiasis: analysis of our series and review of the literature. Journal of endourology / Endourological Society 26: 38-44. 